\title{
Veblen e o Institucionalismo Centrado no Comportamento e na Cultura dos Indivíduos
}

\section{Veblen and Institutionalism Centered on the Behavior and Culture of Individuals}

\author{
Elisa Padilha Garcia ${ }^{\mathrm{a}}$ \\ Octavio A. C. Conceição $O^{b, c}$
}

\begin{abstract}
Resumo: Este trabalho busca analisar os hábitos mentais institucionalizados decorrentes da formação histórica e cultural da sociedade sob a ótica da perspectiva institucionalista e evolucionária de Thorstein Veblen. Visando alcançar esse objetivo, buscase apresentar os principais traços conceituais da respectiva abordagem, a partir de seu clássico A teoria da classe ociosa. Para tanto, busca-se descrever os principais conceitos de Veblen, destacando-se os hábitos culturais e institucionais constituídos pela própria formação histórica da sociedade. Por essa razão, como reflexo dos hábitos mentais e das escolhas culturais, morais e comportamentais dos indivíduos, erigem-se instituições que são desiguais por definição, já que decorrem de padrões socioculturais historicamente constituídos.
\end{abstract}

Palavras-chave: Economia institucionalista. Economia evolucionária. Thorstein Veblen. História econômica.

\begin{abstract}
This study intends to examine institutionalized mental habits as a consequence of the historical and cultural formation of the own society, under the optical of the Evolutionary and Institutionalist perspective of Thorstein Veblen. In order to achieve this objective we present the main notions of this approach departing from The theory of leisure class. That is the reason why the mental habits, the moral and culture choice and the behavior of the individuals became institutions which are unequal by definition, since them are derived from historically constituted sociocultural patterns.
\end{abstract}

Keywords: Institutionalist economy. Evolutionary economics. Thorstein Veblen. Economic History.

JEL Classification: B15; B25; B52.

a Universidade Federal do Rio Grande do Sul (UFRGS), Pró-Reitoria de Extensão (PROREXT), Departamento Administrativo e de Registro da Extensão, Seção de Registro da PROREXT. Porto Alegre, Rio Grande do Sul, Brasil.

b Universidade Federal do Rio Grande do Sul (UFRGS), Faculdade de Ciências Econômicas (FCE), Departamento de Economia e Relações Internacionais. Porto Alegre, Rio Grande do Sul, Brasil.

c Conselho Nacional de Desenvolvimento Científico e Tecnológico (CNPq). Brasília, Distrito Federal, Brasil. 


\section{Introdução}

O presente artigo não pretende esgotar o extraordinário manancial teórico disponibilizado pela contribuição de Thortein Veblen, que inaugurou o que posteriormente se designou de Original Institutional Economics. Não se fará isto em função dos limites teóricos e metodológicos a seres desenvolvidos neste artigo. O que se procurará focar aqui serão as importantes mediações sociais levantadas pelo referido autor em sua obra clássica de 1899, A teoria da classe ociosa.

Não é demais mencionar que Veblen tem sido um autor muito estudado e referido, inclusive no âmbito nacional. Vários estudos recentes têm se debruçado sobre seu pensamento, permitindo avanços na agenda de pesquisa institucionalista, centrada na linha de pensamento vebleniana.

O artigo, em linhas gerais, procura explicitar os seguintes objetivos específicos: a) apresentar os fundamentos da Teoria Institucionalista Evolucionária de Veblen; b) descrever seus principais conceitos, tais como os de instintos, hábitos mentais e instituições; c) retratar as etapas da história cultural da humanidade; d) descrever a divisão de classes; e) abordar os conceitos de ócio e consumo conspícuos, exemplificando-os com a moda de vestuário; f) relacionar as instituições aos indivíduos como um processo evolutivo adaptativo; g) entender de que modo surge a classe ociosa.

\section{Institucionalismo Evolucionário de Veblen}

Durante o final do século XIX, a Teoria da Evolução fundamentada por Charles Darwin influenciou a filosofia e a teoria social da época. Tal influência manifestou-se sobre o conhecimento de Veblen, conduzindo seu posicionamento teórico a uma ótica pós-darwiniano. Nesse sentido, ele via a sociedade como um organismo complexo em incessante busca de mudanças e adaptações às novas circunstâncias (HUNT, 2005). Desse modo, através de uma explicação baseada em cadeias contínuas de causa e efeito (HODGSON, 2003), alegava que a vida econômica dos homens, tal como a vida de outras espécies, é uma luta pela existência, sendo a evolução da estrutura social, por conseguinte, um processo cumulativo de seleção adaptativa, ou seja, uma seleção natural de instituições (VEBLEN, 1983). Isso, no entanto, não significa que as instituições sejam rígidas, mas sim que têm mudanças graduais que pressionam o sistema através de uma tensão entre rupturas, crises e regularidade, exigindo constantes reavaliações e alterações de condutas rotinizadas e de decisões, levando cumulativamente a mudanças de paradigmas (CONCEIÇÃO, 2002b).

Thorstein Veblen, economista e sociólogo, formado em filosofia, americano, filho de noruegueses, também publicou antes da Teoria da Classe Ociosa (Theory 
of the leisure class, 1899), seu ensaio Why is economics not an evolutionary science? (1898), seguido, dentre outras obras, de The theory of business enterprise (1904) e The instinct of workmanship and the state of the industrial arts (1914).

Veblen estabeleceu uma fina e original morfologia econômica e social na qual, discordando da hegemonia econômica, os indivíduos - segundo o pensamento neoclássico já de sua época - eram subentendidos como dados, sem preferências, gostos ou padrões diferenciados de consumo e de escolha. Para ele, os indivíduos deveriam estar no centro da teoria econômica, a qual, portanto, capacitá-los-ia a assumir contornos derivados das idiossincrasias do comportamento humano. Esse argumento antecipou uma série de conceitos que só foram elaborados e incorporados teoricamente em meados do século XX, como as noções de imperfeições de mercado, racionalidade limitada e oportunismo.

Veblen via os hábitos dos indivíduos como elemento central da análise econômica porque estabeleceriam padrões de comportamento, normas de conduta e herança cultural que, interagindo coletivamente, produziriam as instituições.

Estabeleciam-se, assim, os princípios do que, anos mais tarde, Hamilton veio a designar de economia institucional. Esta incorporava noções que, com o tempo, foram ganhando robustez conceitual e analítica, avançando em linha oposta ao pensamento hipotético-dedutivo do neoclassicismo. Fundamentava-se, então, não apenas em princípios matemáticos, derivados da otimização racional de indivíduos hipotéticos e sem preferências, mas na necessidade de se compreender a interação derivada da relação indivíduo-estrutura.

Além de Darwin, Veblen é também considerado como adepto tanto da filosofia pragmatista de Charles Sanders Peirce ${ }^{1}$ e da psicologia comportamental de William James. Tais influências filosóficas explicitam a amplitude, complexidade e originalidade do seu pensamento. Vários artigos dentro da tradição institucionalista têm tratado de sistematizar a natureza do respectivo pensamento (HAMILTON, 1919; COMMONS, 1931; SAMUELS, 1995; HODGSON, 1993, 1998, 2000 apud SALLES et al., 2017). Tais inserções constituem-se em tentativas de avançar no campo analítico da economia institucional, sob um enfoque diferente da nova economia institucional (NEI).

Apesar de Veblen estar associado ao Original Institutional Economics, o termo institutional economics (IE) foi originalmente empregado por Walton Hamilton em seu artigo clássico de 1919. Para ele, tal noção poderia unificar a ciência econômica através da sua articulação entre as partes e o todo. Nesse sentido, advertia

$1 \quad$ O pragmatismo é um pensamento filosófico criado, no fim do século XIX, pelos filósofo americano Charles Sanders Peirce (1839-1914), psicólogo William James (1844-1910) e jurista Oliver Wendell Holmes Junior (1841-1935). Tal pensamento se opunha ao intelectualismo, enfatizando o valor prático como critério da verdade. O pragmatismo busca o caráter de ser prático, pragmático, enquanto aproximação do critério de ser realista. Assim, o valor prático constitui o melhor critério de aproximação do critério da verdade. 
que a IE não poderia assumir um caráter prescritivo em termos de proposições econômicas. Daí sua preocupação com a unificação teórica, que se constituiria na base para a política (propositiva). Ou seja, as proposições deveriam estar assentadas em uma teoria econômica institucional, que, por definição, relaciona instituições e indivíduos na forma do comportamento humano: isso constituiria o legado original do institucionalismo.

Veblen (2017) se opunha às premissas da ortodoxia econômica de sua época, que se sustentavam em hipóteses psicológico-comportamentais diversas do funcionamento real da economia. Em Why is economics not an evolutionary science, escrita em 1898, expôs os três alvos de sua crítica a essa ciência não evolucionária:

a) o animismo: a teleologia decorrente desse tipo de ciência, que visaria a explicação dos fenômenos em termos de uma finalidade;

b) a taxonomia: construção teórica fundamentada no dedutivismo dos fenômenos econômicos a partir de axiomas gerais, como, por exemplo, o homo economicus e a concorrência perfeita;

c) o hedonismo: psicologia que vê o agente econômico como alguém capaz de calcular dor e prazer, de forma a minimizar o primeiro e a maximizar o último. ${ }^{2}$

A partir dessa crítica, Veblen propôs, em contraposição aos neoclássicos, uma reformulação da teoria econômica que se fundamentasse em uma ciência evolucionária, uma ciência empírica que seria uma "[...] teoria do processo, de uma sequência que se desdobra [...]” (VEBLEN, 2017, p. 375), na qual os instintos, hábitos e instituições teriam funções semelhantes às dos genes da biologia na evolução da economia (CONCEIÇÃO, 2002b).

Em sua teoria dos instintos, os indivíduos agiriam sob instintos ou propensões inatas, sobre os quais não possuem controle, sendo os principais os seguintes:

a) workmanship: é o instinto de artesanato ou de trabalho eficaz, ou seja, inclinação para a produção eficaz e repugnância ao esforço fútil;

b) parental bent: é o instinto familiar, ou a tendência inata do homem para se importar com o bem-estar familiar e social;

c) idle curiosity: é o instinto de curiosidade vã, aquilo que levaria o indivíduo a interpretar o mundo de forma condizente, buscando e valorizando o conhecimento de modo instintivo;

d) predatory: é a disposição do indivíduo de valorizar a proeza em detrimento do trabalho rotineiro, após as condições de subsistência estarem garantidas (MONASTERIO, 1995).

Partindo da ideia de indivíduos motivados por esses instintos, Veblen define hábitos mentais como padrões de conduta que especificam os meios a serem usa-

2 Cabe referir que a mencionada obra encontra-se atualmente disponível em português em livro editado recentemente no Brasil sobre o velho institucionalismo. Esse e outros artigos clássicos dos antigos institucionalistas podem ser encontrados em Salles (2017). 
dos com vistas a satisfazer seus instintos, que passam por um processo contínuo no qual são mantidos ou alterados ao longo do tempo pelos próprios indivíduos, permitindo sua adaptação às circunstâncias adversas (VEBLEN, 1983). O indivíduo tende a preservar o hábito, tendo-o arraigado em seu espírito, alterando-o apenas com inércia e relutância quando as situações o obrigam a tal. Assim, a concepção vebleniana de instituição é dada pelos hábitos mentais determinados de forma coletiva, que se tornam hábitos institucionalizados (MONASTERIO, 1995).

Segundo Hodgson (2003), o que torna o trabalho de Veblen único e excepcional é a sua atenção aos processos de causalidade e os mecanismos psicológicos pelos quais o indivíduo é adaptado pelas circunstâncias. Segundo Veblen (1983), os instintos humanos são compostos, simultaneamente, por ações teleológicas e ações inconscientes ou tropismáticas. Por seu turno, os hábitos mentais são formados a partir de uma conexão entre essas propensões instintivas e as condições sociais, adquiridas de um passado recente, que influem na tomada de decisões. Esta última é realizada através da racionalidade humana, cujo papel é de mediação entre os tropismos e os elementos teleológicos.

Veblen via a história humana como a história da evolução das instituições sociais. O comportamento humano, portanto, se fundamentava em certos padrões comuns a todas as épocas históricas, que se expressavam de formas diferentes, em contextos históricos, sociais e institucionais também diversos (HUNT, 2005). Ao conectar suas duas unidades de análise, indivíduos e sociedade, através de seus hábitos e instituições, respectivamente, em uma teoria econômica evolutiva, constituía uma junção das análises micro e macroeconômica (HODGSON, 1998).

Nesse sentido, criou uma tipologia histórica diferenciada em relação às clássicas sucessões dos modos de produção, como a proposta por Marx. Veblen (1983) dividiu a história cultural da humanidade em cinco diferentes estágios de desenvolvimento econômico e social: cultura selvagem; cultura bárbara primitiva e quase pacífica; cultura bárbara intermediária e pacífica; cultura bárbara avançada ou feudal; e cultura moderna industrial. ${ }^{3}$ Vejamos cada um deles sucintamente.

O estágio cultural mais primitivo, pertencente ao homem selvagem, é composto por grupos diminutos e pobres, pacíficos e sedentários, de estrutura simples e arcaica, cuja economia não tem a propriedade como traço marcante, sendo seus membros incapazes de resistir a ataques de outros povos. Essa fase é marcada pela inexistência de uma classe ociosa e de uma atitude espiritual que apoie sua instituição e, portanto, não há uma divisão de trabalho. O indivíduo mostra eficiência em sua colaboração na vida do grupo. A competição econômica existente entre

3 Em oposição à dicotomia entre os vários estágios das forças produtivas que se articulariam com os diferentes tipos de relações sociais de produção, definindo os modos de produção, Veblen parte dos vários padrões culturais, que, por meio de hábitos e instintos, definiriam os estágios de desenvolvimento. Nele, os hábitos e padrões comportamentais dos indivíduos definiriam as instituições, as quais, por sua vez, assegurariam a fluidez do sistema. 
os membros da tribo é realizada através de emulação em serviço industrial, sendo esta fracamente estimulada.

Na segunda etapa, entra-se na cultura bárbara primitiva, quase pacífica, ou regime de status, na qual o aparecimento de uma classe ociosa coincide com o início da propriedade. A propriedade de mulheres começa com o hábito de apropriação violenta das esposas cativas do inimigo, utilizadas como troféus, costume que resultou em uma forma de casamento-propriedade, com a formação de uma estrutura familiar sob o comando de um homem. Assim, apesar de a divisão de trabalho ainda ser pouco definida, surge uma especialização de funções e uma divisão de classes, cuja classe dominante é formada pelos homens, que têm a função de caçar e lutar, e a classe trabalhadora abrange todas as mulheres, cujas funções são aquelas relativas à submissão e à subserviência, monótonas e rotineiras. A base da honorabilidade nessa etapa é a agressão, e a consequência da emulação foi, de um lado, um modo de casamento fundado na coerção, e de outro, o hábito da propriedade da mulher, sendo ainda impossível distinguir ambas as instituições. A emulação pecuniária é feita através da comparação entre o possuidor da presa honorífica e os seus companheiros de tribo menos capazes, e se prende à utilidade da coisa apreendida, sendo o seu dono o guardião da honra do grupo.

$\mathrm{Na}$ cultura bárbara intermediária e pacífica, a propriedade se estendeu à escravidão de outros cativos e dependentes, além das mulheres, desenvolvendo-se, afinal, o casamento-propriedade a outras mulheres além das tomadas pelo inimigo. Passa a haver, então, uma divisão de classes entre a classe superior, formada pelos homens, e a classe inferior, formada pelos escravos, dependentes e mulheres. A base convencional da honorabilidade vem a ser a proeza e a eficiência predatória. A divisão do trabalho, então, se distribui entre as ocupações honoríficas, que consistem naquelas atividades predatórias, que demonstram força, coerção, prepotência, decorrentes de rapina, competição e agressão contra homens e animais, que significam proeza, dignidade e prestígio entre o grupo social, e as ocupações produtivas, que são aquelas que demandam regularidade e uniformidade, tais como as tarefas manuais, industriais e de subsistência, e são consideradas indignas, desagradáveis, humilhantes, tediosas e desonrosas pela comunidade.

O estágio de cultura bárbara avançada, que é representado pelo feudalismo, foi quando a classe ociosa foi instituída. Nesta, o conceito de propriedade se estende da propriedade de mulheres para incluir a propriedade dos produtos de sua indústria, resultando daí a propriedade das coisas, além da propriedade de pessoas. O ócio passa a ser, assim, a base convencional da honra e expressão econômica de superioridade. Enquanto a classe ociosa é formada pelas classes nobres, sacerdotais e seus respectivos agregados e realiza atividades intrinsecamente honoríficas, que são as não industriais, tais como as ocupações governamentais, guerreiras, religiosas e esportivas, a classe inferior é formada pela população plebeia, que re- 
aliza as atividades industriais, vistas como odiosas e indignas de um homem capaz. Durante essa fase, passa-se a ver como igualmente prestigiosos até mesmo os instrumentos e acessórios de guerra, tais como as armas e sua utilização, a fabricação e o cuidado de armas e equipamentos guerreiros e de barcos de guerra, o manejo e o cuidado de cavalos, cães e falcões, o preparo de utensílios sagrados.

Na vida moderna, essa discriminação persiste como preconceito corriqueiro, o que é demonstrado pela habitual aversão por tarefas servis. A guerra, a política, os rituais religiosos, a caça, os esportes e os espetáculos populares são tidos ainda como intrinsecamente diferentes do trabalho necessário para a consecução dos meios materiais da vida.

Na moderna cultura industrial, a propriedade se torna uma instituição humana sem relação com o mínimo de subsistência. A classe ociosa é formada pelos ricos e a classe inferior, pelos pobres. A base consuetudinária da dignidade, decência, honra, reputação social e sucesso é a posse da riqueza e a consequente aquisição de bens materiais, tanto por herança quanto por esforço próprio, enquanto as atividades indignas são as servis, manuais e industriais. Os membros do grupo social que não atingem o padrão de riqueza sofrem na estima de seus companheiros e na sua própria estima, já que o requisito da autossatisfação é o respeito dos outros. A propriedade de bens assume valor, não tanto como prova de sucesso, mas como prova de prepotência do possuidor sobre os outros membros da comunidade. A emulação pecuniária passa a ser uma luta pela riqueza e pelo sucesso, que se dá através da competição pelo aumento dos confortos da vida, principalmente pelo aumento dos confortos físicos que o consumo de bens proporciona. Em outras palavras, a propriedade de bens, como um troféu, se torna a única prova evidente de realização heroica e notável e de posição social.

Veblen (1983, p. 19) explica a emulação pecuniária nessa etapa da cultura industrial da seguinte forma:

[...] há uma tendência constante no sentido de fazer de cada padrão pecuniário o ponto de partida para um novo aumento de riqueza; o novo padrão, por sua vez, produz um novo critério de suficiência e uma nova classificação pecuniária em relação aos vizinhos. Relativamente à questão ora discutida, o fim da acumulação de riquezas é sempre uma autoclassificação do indivíduo em comparação com o resto da comunidade no tocante à força pecuniária. O indivíduo normal, enquanto tal comparação lhe é distintamente desfavorável, vive cronicamente descontente com a própria situação; logo que ele atinge o que pode chamar o padrão pecuniário médio da comunidade ou de sua classe na comunidade, aquele descontentamento crônico se transforma num esforço impaciente para se distanciar cada vez mais de tal padrão. A comparação odiosa entre os indivíduos nunca se torna tão favorável a um deles, que este se descuide de tentar colocar-se ainda mais alto relativamente a seus concorrentes na luta pela honorabilidade pecuniária. 
O Quadro 1 procura expor as cinco etapas mencionadas, resumindo seus principais elementos e características.

Quadro 1 - Etapas evolutivas da cultura de Veblen

\begin{tabular}{|c|c|c|c|c|c|}
\hline Etapa cultural & $\begin{array}{c}\text { Selvagem } \\
\text { pacífica } \\
\text { sedentária }\end{array}$ & $\begin{array}{c}\text { Bárbara pri- } \\
\text { mitiva quase } \\
\text { pacífica }\end{array}$ & $\begin{array}{c}\text { Bárbara in- } \\
\text { termediária } \\
\text { pacífica }\end{array}$ & $\begin{array}{c}\text { Bárbara } \\
\text { avançada } \\
\text { feudal }\end{array}$ & $\begin{array}{c}\text { Moderna } \\
\text { industrial }\end{array}$ \\
\hline $\begin{array}{l}\text { Propriedade } \\
\text { privada }\end{array}$ & $\begin{array}{l}\text { Propriedade } \\
\text { privada } \\
\text { inexistente. }\end{array}$ & $\begin{array}{l}\text { Propriedade de } \\
\text { mulheres do } \\
\text { inimigo. }\end{array}$ & $\begin{array}{l}\text { Propriedade de } \\
\text { pessoas: escra- } \\
\text { vos, dependen- } \\
\text { tes e mulheres. }\end{array}$ & $\begin{array}{l}\text { Estende-se da } \\
\text { propriedade de } \\
\text { mulheres para a } \\
\text { propriedade dos } \\
\text { produtos de sua } \\
\text { indústria. } \\
\end{array}$ & $\begin{array}{c}\text { Propriedade } \\
\text { de } \\
\text { bens. }\end{array}$ \\
\hline $\begin{array}{l}\text { Ocupações } \\
\text { dignas }\end{array}$ & \multirow[t]{2}{*}{$\begin{array}{l}\text { Distinção } \\
\text { de funções } \\
\text { inexistente. }\end{array}$} & \multirow[t]{2}{*}{$\begin{array}{l}\text { Distinção pou- } \\
\text { co definida. Es- } \\
\text { pecialização de } \\
\text { funções mascu- } \\
\text { linas (caça) ver- } \\
\text { sus femininas } \\
\text { (monótonas e } \\
\text { rotineiras). }\end{array}$} & $\begin{array}{l}\text { Atividades pre- } \\
\text { datórias, que } \\
\text { exigem demons- } \\
\text { tração de força, } \\
\text { proeza, prepo- } \\
\text { tência, coerção, } \\
\text { rapina, agressão } \\
\text { contra homens } \\
\text { e animais, com- } \\
\text { petição: gover- } \\
\text { namentais, guer- } \\
\text { reiras, religiosas } \\
\text { e esportivas. } \\
\end{array}$ & $\begin{array}{l}\text { Ocupações não } \\
\text { industriais, tais } \\
\text { como governa- } \\
\text { mentais, guer- } \\
\text { reiras, religiosas } \\
\text { e esportivas. }\end{array}$ & \begin{tabular}{|c} 
Trabalhos \\
que sugerem \\
sucesso, \\
mérito, \\
decência, \\
estima e \\
reputação \\
social: posse \\
da riqueza e \\
acumulação \\
de bens.
\end{tabular} \\
\hline $\begin{array}{l}\text { Ocupações } \\
\text { indignas }\end{array}$ & & & $\begin{array}{l}\text { Trabalhos ma- } \\
\text { nuais, industriais } \\
\text { e de subsistên- } \\
\text { cia, que exigem } \\
\text { assiduidade, } \\
\text { uniformidade e } \\
\text { continuidade. } \\
\end{array}$ & $\begin{array}{l}\text { Trabalhos } \\
\text { manuais, servis } \\
\text { e industriais. }\end{array}$ & $\begin{array}{c}\text { Trabalhos } \\
\text { manuais, } \\
\text { servis e } \\
\text { industriais. }\end{array}$ \\
\hline $\begin{array}{l}\text { Distinção de } \\
\text { classes }\end{array}$ & $\begin{array}{c}\text { Inexistência } \\
\text { de uma } \\
\text { classe ociosa } \\
\text { e de uma } \\
\text { atitude } \\
\text { espiritual que } \\
\text { apoie essa } \\
\text { instituição. } \\
\end{array}$ & $\begin{array}{l}\text { Classe superior: } \\
\text { homens. } \\
\text { Classe inferior: } \\
\text { mulheres. }\end{array}$ & \begin{tabular}{|c} 
Classe superior: \\
homens \\
das classes \\
superiores. \\
Classe inferior: \\
escravos, \\
dependentes e \\
mulheres. \\
\end{tabular} & $\begin{array}{l}\text { Classe ociosa: } \\
\text { nobres, } \\
\text { sacerdotes e } \\
\text { agregados. } \\
\text { Classe } \\
\text { trabalhadora } \\
\text { inferior: } \\
\text { plebeus. } \\
\end{array}$ & $\begin{array}{l}\text { Classe } \\
\text { ociosa: } \\
\text { ricos. Classe } \\
\text { trabalhadora } \\
\text { inferior: } \\
\text { pobres. }\end{array}$ \\
\hline Base da honra & $\begin{array}{c}\text { Colaboração } \\
\text { com o grupo } \\
\text { social. }\end{array}$ & Agressão. & $\begin{array}{c}\text { Proeza e } \\
\text { eficiência } \\
\text { predatória. }\end{array}$ & Ócio. & $\begin{array}{c}\text { Riqueza e } \\
\text { aquisição } \\
\text { de bens } \\
\text { materiais, } \\
\text { por herança } \\
\text { ou esforço } \\
\text { próprio. }\end{array}$ \\
\hline
\end{tabular}

Fonte: Elaboração própria a partir de Veblen (1983).

Depois da análise das diferentes etapas evolutivas da cultura expostas por Veblen, o próximo tópico parte para a explicação vebleniana acerca da distinção entre classes. 


\subsection{Classe Ociosa versus Classe Trabalhadora}

As classes pecuniárias inferiores, cujo meio para a aquisição de bens é o trabalho produtivo, não podem evitar o trabalho, não sendo este visto como vergonhoso, pelo menos entre essas classes. Pelo contrário, sendo o trabalho o seu padrão de vida reconhecido e aceito, os indivíduos se orgulham de suas aptidões para o trabalho produtivo, por ser essa a única forma de emulação que lhes é possibilitada.

Já para as classes pecuniárias superiores, a tradição da cultura predatória perdura até hoje, dado que o trabalho produtivo ainda é visto como indigno e humilhante. Com a intensificação da discriminação social, essa ideia obteve uma força axiomática que tornou sua vigência inquestionável na sociedade ao longo do tempo. Para essas classes, para obter e manter a estima de seu grupo social não é necessário somente possuir riqueza ou poder, mas também que a posse dessa riqueza e desse poder esteja explícita aos outros, para servir como prova de riqueza tanto para satisfazer aos outros quanto a si próprio.

Até o presente, os indivíduos têm em seus hábitos mentais a ideia de condenação e desprezo aos ambientes populares, aos domicílios baratos e aos empregos manuais e industriais, pois não seriam condizentes com uma vida espiritual elevada. Dito em outros termos, Veblen (1983, p. 22) destaca que "[...] têm os homens ainda hoje um sentido ritualístico de imundícia ligado de modo fortíssimo às ocupações que, nos nossos hábitos de pensamento, têm que ver com trabalhos vis".

Por seu turno, uma vida de ociosidade é avistada como um ideal de beleza e nobreza a ser seguido, sendo considerada convencionalmente não apenas como a melhor forma de evidenciar força pecuniária, força superior e posição social, mas também como um requisito para a decência.

Na medida em que cresce a população e a cultura evolui de predatória para industrial, as autoridades instituídas e as normas que regulamentam a propriedade ganham forma, tornando impossivel aos homens de espírito elevado e aos pobres atingir a riqueza, nem através de apropriação, nem da indústria, restando como última alternativa a privação ou a mendicidade. Destarte, sempre que a inclinação ao ócio conspícuo se aproxima de um ambiente favorável ao seu desenvolvimento, instaura-se uma classe ociosa secundária espúria, conceituada por Veblen (1983, p. 24) como "[...] uma classe desprezivel e pobre que vive precariamente em desconforto e pobreza e que é moralmente incapaz de se ocupar de atividades lucrativas.".

\subsection{A Ociosidade Conspícua}

O membro da classe ociosa não passa todo o seu tempo à vista dos outros, visando demonstrar-lhes sua vida de ócio honorífico. Ele, diversamente, gasta certa parcela de seu tempo longe do público e, por isso, se desdobra em manifestar de 
modo persuasivo aos espectadores seu costume de passar esse tempo desocupado. Para demonstrar sua isenção conspícua de todo trabalho útil, utiliza meios indiretos, tais como a exibição dos servos que emprega, os bens resultantes de seu trabalho, assim como outros meios imateriais, como, por exemplo, os talentos eruditos ou artísticos, o conhecimento de idiomas em desuso, de ciências ocultas, das regras de ortografia, sintaxe e prosódia, da música e outras artes, da moda de vestuário, do mobiliário, de jogos, esportes e animais de raça, tais como cães e cavalos de corrida. Contudo, o principal método de provar o ócio, naqueles estágios de cultura em que o ócio conspícuo é mais utilizado, ou seja, em um regime de status, são as regras da educação, da polidez, de decoro e cerimonial, dado o prestígio que sinalizam como impressão de respeitabilidade pecuniária e de posicionamento social.

Esses códigos de etiqueta expressam uma relação de status que simboliza o domínio, de um lado, e a submissão, de outro, e são entendidos popularmente, até os dias de hoje, como um traço integrante da dignidade humana, que tem uma utilidade intrínseca e um caráter sagrado. $\mathrm{O}$ fundamento econômico encontrado na busca rígida pelo cumprimento de tais regras está associado ao estágio cultural bárbaro primitivo e quase pacífico, devido ao caráter honorífico do ócio, no qual há o emprego de tempo e esforço em atividade não produtiva. Assim, conforme atesta Veblen (1983, p. 26-27), "Os gostos refinados, as boas maneiras e os hábitos requintados de vida são sinal útil de bom nascimento, porque a boa educação requer tempo, esforço e dinheiro, estando fora do alcance dos que têm todo o seu tempo e energia ocupados com o trabalho".

A presença da vida ociosa em uma família durante várias gerações conduz a uma conformação individual em relação aos hábitos de comportamento. Desse modo, o ócio conspícuo, do qual a etiqueta é uma ramificação, se torna um processo constante de esforço pela busca do esnobismo, isto é, pelo requinte na conduta, por um ensino do bom gosto e por uma sensibilidade nas decisões e hábitos de consumo.

A relação de status presente no decoro revela o domínio da figura do senhor, representante da classe ociosa mais alta, a qual não possui superiores e contém poucos pecuniariamente iguais, e é quem determina as normas e os padrões de comportamento econômico e social que deve ser seguido pelas classes inferiores, formada pelos seus criados e dependentes.

A posição excepcional do senhor na sociedade exige a posse de uma quantidade cada vez maior de servos domésticos especializados à sua disposição, que se tornam um meio de ostentação e de prazer por serem requisitos para o exercício de seu instinto de domínio. A quantidade cada vez maior de servos acarreta uma diferenciação de funções entre eles, o que os isenta cada vez mais de ocupações produtivas. Assim, sua utilidade passa a ser somente a honrosa isenção de trabalho produtivo, denominada de ócio vicário, e o fato de essa isenção conferir ao senhor uma prova de riqueza supérflua, poder e capacidade de consumir improdutivamente uma grande quantidade de serviços. 
Surge, assim, uma classe ociosa subsidiária, denominada vicária, que é composta pelas esposas e os criados domésticos livres, cuja única função é o ócio vicário em proveito da respeitabilidade pecuniária da classe ociosa principal, já que determinado tempo e esforço é desperdiçado conspicuamente em seu favor. Além disso, a atitude de subserviência e a demonstração de que se foi devidamente treinado para tal constituem os principais elementos da utilidade dos criados e os principais dotes de uma boa esposa. O desempenho inadequado e sem o cumprimento das normas da etiqueta indicam a incompetência, por parte do senhor, de manter criados especialmente treinados ou esposas bem-educadas, denotando sua falta de recursos suficientes para tal padrão de riqueza.

A classe ociosa principal se distingue, porém, da classe ociosa vicária, pois, enquanto, na primeira, o ócio do senhor busca evitar qualquer tipo de trabalho, aumentando seu próprio bem-estar e opulência, na última, o ócio é necessário e obrigatório aos criados, tendo em vista não o seu próprio conforto, mas o do senhor a quem são subordinados.

Nos dias atuais, o ócio abrange todos os membros da organização familiar, e não apenas o senhor. Assim, o emprego de criados domésticos é justificado pela impossibilidade de os membros da família executarem o trabalho doméstico necessário sem desconforto. Segundo o seu código de etiqueta, dada a necessidade moral de respeitabilidade pecuniária, a família necessita gastar seu tempo e esforço em ócio conspícuo, seja em passeios, clubes, esportes, organizações filantrópicas, entre outros; e em consumo conspícuo de bens, como, por exemplo, em móveis, vestuários e refeições.

\subsection{Consumo Conspícuo}

O padrão de vida de uma comunidade se origina do hábito de resposta a determinado estímulo. Assim, o padrão habitual de vida que rege os estímulos dos indivíduos na sociedade não são aqueles gastos de subsistência, que já foram alcançados, mas sim os gastos supérfluos, que se motivam pelo impulso da competição, definida como o hábito de comparação invejosa que desafia os indivíduos a superar os outros membros de sua classe, assim como cada classe a superar a classe imediatamente acima desta na hierarquia social. Esse dispêndio, denominado consumo conspícuo, é o que concede decência, honra e respeitabilidade a um indivíduo em relação aos outros componentes do grupo.

Cada classe social, a partir do instinto predatório, adquire o poder de definir e controlar o padrão de vida, as circunstâncias econômicas, as tradições e o grau de maturidade espiritual que todas as classes inferiores deverão se adaptar e assumir como atitudes, hábitos e condutas dignas e honoráveis, servindo de exemplos e normas de comportamento. 
Quanto mais antigos e arraigados pela sociedade forem os hábitos, mais serão inalteráveis, persistentes e dominantes, isto é, maior relutância o indivíduo terá em abandoná-los. Além do tempo, também influem na continuidade e na dominância do hábito as tendências espirituais e temperamentais herdadas pelos indivíduos.

Após o instinto de autopreservação da espécie, o instinto para a competição é o mais forte e imperante dos motivos econômicos. Em uma comunidade industrial, a referida propensão é manifesta na concorrência pecuniária através do consumo conspícuo.

Visto que uma maior eficiência industrial permite a obtenção dos meios de sobrevivência com maior facilidade, os esforços se direcionarão ao gasto conspícuo, e não a uma busca pelo conforto doméstico, pois este aspecto é considerado insignificante perto da aceitação social por parte dos observadores de sua ostentação. A norma que regula o consumo é uma exigência do consumo conspícuo, ou seja, do dispêndio supérfluo destinado à ostentação. Dessa maneira, a razão do consumo é um desejo de estar em conformidade com o hábito consagrado e aceito pela comunidade, visando escapar de comentários críticos e desfavoráveis dos outros.

\subsubsection{Código de Conduta Estética e a Moda}

Sob a lei seletiva do consumo conspícuo, há um código de regras de decência que rege o consumo, determinando a quantidade e a qualidade dos produtos a serem comprados, geralmente supérfluos e de alto custo.

Em culturas industriais modernas, nas quais prevalece a lei da inviolabilidade da instituição da propriedade privada, há um outro hábito mental decorrente: o da busca pela riqueza visando a construção de uma boa reputação a partir do dispêndio conspícuo. Essa regra social intervém no senso dos indivíduos em relação ao dever, gosto, beleza, utilidade, devoção religiosa e ciência.

Em relação ao critério de opinião sobre a beleza intrínseca dos artigos de consumo, em especial aqueles relacionados à moda de vestuário e de móveis, tende-se, de forma inconsciente, a confundir a beleza à superfluidade, ou seja, a considerar um produto belo não por seu valor de uso, mas pela onerosidade, emulação e desperdício conspícuo que comunica aos outros. Dessa forma, a beleza é apenas um instrumento para mascarar o preço elevado do bem consumido. Por ser um hábito calcado no caráter honorífico, a regra do gosto se transforma em uma norma que constrange, discrimina ou orienta seletivamente o comportamento dos indivíduos.

O consumo conspícuo com vistas à ostentação e à emulação é mais praticado no setor de vestuário do que em qualquer outro setor de consumo. O código de conduta honorífica referente ao vestuário determina, para todas as camadas sociais, os modelos, cores e matérias-primas que deverão ser consumidos em determinada temporada do ano. A pessoa que compra vestuário conspicuamente 
oneroso busca a aceitação social e o sucesso pecuniário, dados pela conformidade ao padrão de gostos adotado, sendo qualquer desvio dessa regra alvo de censura e de descrédito pecuniário pelos outros.

Veblen (1983, p. 78) procura demonstrar esse código de conduta do gosto através de um exemplo prático, que é a rejeição do produto vulgar e a preferência pelo mais dispendioso:

[...] todos achamos um artigo de vestuário de alto preço e feito a mão preferível, em questões de beleza e utilidade, a uma imitação menos dispendiosa do mesmo, por mais inteligentemente que o artigo espúrio possa imitar o caro original; e o que ofende a nossa sensibilidade no artigo espúrio não é o fato de ele ser inferior em sua forma ou cor, ou, de qualquer modo, em seu efeito visual. O objeto que nos repugna pode até ser uma imitação tão perfeita, ao ponto de desafiar o mais severo escrutínio; todavia, nem bem a contratação é percebida, o seu valor estético, assim como o seu valor comercial, declina precipitadamente.

Quem usa o vestuário da moda demonstra aos outros que tem a capacidade de gastar livremente, sem necessitar ganhar a vida através de trabalho produtivo. Para que atinja tal sugestão de ócio, o traje deverá ser limpo e novo, de maneira que tenha uma aparência agradável e elegante.

Tendo em conta a elegância e a polidez demandadas à emulação, a utilização habitual de barba, chapéu e bengala pelo homem pertencente à classe ociosa está diretamente relacionado à ideia de sua desnecessidade de trabalho produtivo. Da mesma forma, o uniforme utilizado pelos criados domésticos requer também a mesma desnecessária ostentação de gastos, a dependência servil e vicária e o desconforto de seus usuários.

No entanto, a moda afeta sobretudo as mulheres, uma vez que seu papel era, ao longo das fases culturais, o da servidão doméstica, da dependência econômica e do consumo vicário da ociosidade do marido, sendo o uso de vestidos, corpetes, chapéus largos e salto alto exemplos de vestimentas incômodas que aumentam a incapacidade para o trabalho, de forma que seja visível aos observadores.

As condições de elegância e de desconforto, porém, representam um fingimento e uma futilidade tão grandes que se tornam, com o tempo, estilos intoleráveis pela sociedade, e, por conseguinte, busca-se o recurso da inovação para mudar o estilo vigente para outro igualmente fútil e intolerável, fazendo com que a moda se altere sucessivamente a cada estação do ano. Acerca desse dinamismo da moda, Veblen (1983, p. 81) ainda salienta: "A moda prevalecente transmite a sensação de que é bela. Isso em parte se deve ao alívio que ela proporciona por ser diferente do que era antes, e, em parte, por ser bem-conceituada”.

Desse modo, permite-se concluir que o hábito do consumo de vestuário é conduzido por três princípios: o princípio do dispêndio conspícuo, pela exigência de que a roupa deve ter preço elevado; o princípio de ócio conspícuo, pela con- 
dição de desconforto e consequente incapacidade para o trabalho; e, por fim, o princípio de novidade, ligado ao motivo de exibição, que demanda que o traje e o estilo estejam na moda em vigência naquela estação.

A parte da classe ociosa que é isenta de trabalho industrial por mais de uma geração já consegue ser suficientemente volumosa e capaz de impor e preservar o seu juízo sobre a preferência e o gosto dos bens a serem consumidos pela comunidade. Seu intuito é, portanto, atribuir notoriedade e confirmação social ao possuidor de determinado bem oneroso, na medida em que causa uma comparação invejosa com os outros indivíduos do grupo que não o desfrutam.

Quanto ao consumo de móveis, costuma-se dar prioridade aos trabalhados manualmente, em detrimento aos feitos à máquina, devido ao seu alto custo de produção e sua rusticidade que remete ao classicismo, ou seja, à veneração aos elementos arcaicos e obsoletos, característicos da cultura predatória.

Em relação à beleza dos animais domésticos, costuma-se selecionar aqueles que não têm utilidade industrial, tais como aves de gaiola, gatos, cães e cavalos de corrida. Por serem bens de consumo conspícuo, contêm caráter honorífico e são considerados legitimamente belos, pelo alto preço e desperdício que denotam.

Os cachorros são os favoritos nesse sentido, dado que, além de não servirem para fins industriais, estão associados à caça - ocupação de instinto predatório e honorífico. Possuem forte inclinação para a subserviência, dependência e fidelidade ao seu dono e também evidenciam a dignidade implícita na ociosidade do proprietário, na medida em que este lhe dá atenção.

Embora o cavalo de corrida não se comporte com a mesma submissão apresentada pelo cão, também não fornece nenhuma serventia industrial ao dono, além de exigir cuidados altamente custosos em sua manutenção. Desse modo, seu consumo é eficaz na medida em que serve como instrumento de jogo, honra, conspicuidade e emulação para com os outros.

No que toca ao ideal de beleza dos indivíduos, há uma normativa na qual as mulheres são apreciadas em relação à sua performance no ócio vicário, cujo sinal é representado por uma excessiva delicadeza e uma notável incapacidade física e inutilidade para o esforço útil. Nesse sentido, determinados defeitos ou traços patológicos da mulher, provocados inclusive artificialmente, são valorizados por reproduzirem a ideia de que elas necessitam ser mantidas na ociosidade pelo seu proprietário (marido), servindo de prova da força pecuniária deste, pela dispendiosidade no seu sustento. Dentre esses traços requisitados pelos homens, pode-se citar como exemplos a cinturinha de vespa que foi moda em culturas ocidentais por um longo período, assim como as deformações nos pés femininos admirados pela cultura oriental.

Em suma, o princípio que regula a teoria estética está inteiramente ligado ao consumo de artigos caros, atingindo seus dois propósitos: o de meio para ostentações e comparações invejosas e o de prova de habilitação para pagar, que fornece 
um caráter honorífico e meritório ao dono e, inversamente, desaprova as mercadorias úteis e de baixo preço e censura um estilo de vida não dispendioso, que insinua uma certa inaptidão para o gasto supérfluo. Como consequência desse hábito arraigado na sociedade, os produtores direcionam seu foco na fabricação de produtos cuja característica preponderante é o refinamento emulativo e honorífico.

O princípio de reputação com base no dispêndio conspícuo, na medida em que cria julgamentos de valor acerca de vários aspectos, tais como econômicos, morais, estéticos e de respeitabilidade, é uma lei seletiva que testa a adequação às exigências dos indivíduos em um ambiente competitivo entre os demais hábitos. Assim, quanto mais esbanjadora seja a metodologia de vida ou o hábito adotado, maior será a probabilidade de preservação do indivíduo apto em relação a essa norma seletiva.

\subsection{Instituições e Individuos}

O desenvolvimento das instituições e do caráter humano seriam, ao mesmo tempo, uma seleção natural dos hábitos mentais mais aptos e um processo adaptativo compulsório dos indivíduos a um meio ambiente que se altera de modo gradual, devido ao progresso social e às transformações nas instituições.

Para Veblen (1983), as instituições seriam padrões de vida e de relacionamentos sociais decorrentes de um processo de seleção e de adaptação que molda os tipos predominantes de hábitos mentais, ações, comportamentos, opiniões, habilidades e propensões espirituais. Visto que mudam e se desenvolvem, conduzem a uma imediata eleição daqueles indivíduos munidos de temperamento mais apto e apropriado e a uma consecutiva adaptação do temperamento do indivíduo e seus hábitos ao ambiente que se altera, sob pressão das novas circunstâncias, que já não admitem tais hábitos considerados ultrapassados, e, consequentemente, da construção de novas instituições. À vista disso, de acordo com Veblen (1983, p. 88):

As instituições têm de mudar com a mudança das circunstâncias, uma vez que é de natureza do seu método habitual corresponder aos estímulos que essas circunstâncias variáveis lhes proporcionam. O desenvolvimento dessas instituições é o próprio desenvolvimento da sociedade.

A conjuntura vigente, que inclui as instituições válidas em determinada época, oportunizará, mediante o referido processo seletivo e coercitivo, a sobrevivência e a predominância de determinado tipo de caráter, hábito ou opinião do passado em detrimento de outro. O tipo humano escolhido para permanecer e, após, construir as instituições herdadas do passado ajustará essas instituições em sua conformidade. Porém, ao mesmo tempo que há a seleção dos tipos de caráter e de hábitos de pensamento, também ocorre um processo de adaptação seletiva entre hábitos mentais e aptidões peculiares daqueles tipos étnicos predominantes. 
Conforme o próprio autor enfatiza (VEBLEN, 1983, p. 88): "As instituições são o produto de processos passados, adaptados a circunstâncias passadas, e, por conseguinte nunca estão em pleno acordo com as exigências do presente".

Por consequência, as instituições vigentes são, essencialmente, psicologicamente conservadoras e inerciais, visto que tendem a perdurar continuamente, até que um novo cenário os force a mudar, de acordo com as novas exigências. É importante salientar, contudo, que esse reajustamento se dá pela reação a uma pressão externa e com relutância, sob a coerção da nova circunstância, que tornou o paradigma passado insustentável.

O reajuste das instituições habituais em relação a um ambiente modificado é realizado, então, pela reação a uma pressão externa. A partir dessas evoluções e adaptações mentais, a estrutura social também se ajusta e se desenvolve progressivamente, uma vez que as relações externas ficam suscetíveis às alterações processadas nas relações internas. Dessa forma, Veblen (1983, p. 88) afirma que:

[...] o ambiente, a situação, as exigências da vida que obrigam à adaptação e ao exercício da seleção mudam de dia para dia; e cada sucessiva situação da comunidade tende por sua vez para o arcaísmo, nem bem foi adotada. Um passo rumo ao desenvolvimento já por si constitui uma mudança de situação a exigir uma nova adaptação; torna-se, com efeito, um ponto de partida para um novo passo rumo ao ajustamento, e assim por diante, interminavelmente.

O método de vida acolhido por determinado grupo social é dado por um consenso de posicionamentos preservados pela comunidade no tocante ao que é correto, benéfico, propício, adequado ou bonito na vida humana. No que tange aos modelos específicos de comportamento, determinada norma se mantém em vigor apenas quando possui a sustentação do hábito ou da aptidão, que servem de base e critério para seu desdobramento.

Dessa forma, a classe que tenderá a impor seus hábitos, opiniões, interesses e esquema de vida ao ambiente em transformação e, ao mesmo tempo, buscará retardar o processo de mutação social, é a classe ociosa mais alta. Através de seu conservadorismo, essa classe se mantém privilegiada e amparada pelas forças econômicas que orientam as transformações e o reajustamento das instituições. Assim, qualquer mudança sobre o que é bom ou correto na vida humana somente se faz de forma tardia, não apenas porque estará em desacordo com o posicionamento arcaico da classe ociosa, mas também porque o retrocesso de determinado conceito ao qual o ser humano já se acostumou é mais simples de suceder do que o processo seletivo e adaptativo.

Além disso, as exigências econômicas da comunidade não recaem sobre os integrantes da classe ociosa, ou seja, esta não tende a ser coagida, constrangida ou obrigada a alterar seus hábitos mentais ou suas opiniões a respeito do mundo para 
adaptá-las à nova ordem social existente, renovada por inovações sociais, tecnológicas ou industriais, dado que não pertence à comunidade industrial. Portanto, tal como destaca Veblen (1983, p. 91): "O papel da classe ociosa na evolução social consiste em retardar o movimento e conservar o que é obsoleto".

Durante o reajustamento do padrão de vida, as novas condições ambientais podem ser capazes até de favorecer a vida do grupo como um todo, mas poderão desfavorecer a qualidade da vida de alguns indivíduos da comunidade. Geralmente, os indivíduos que necessitam de uma mudança de hábitos e relações sociais sentem a disparidade entre a metodologia de vida tradicional a qual se habituou e aquela metodologia requisitada mais recentemente. Por conta disso, são os membros do grupo que possuem maior motivação para reconstruir o esquema atual de vida e, simultaneamente, são os mais facilmente convencidos a aceitar os novos métodos habituais impostos. A pressão ou força constrangedora empregada pelo ambiente sobre o grupo social, que beneficia o reajuste das instituições, se choca com os componentes desse grupo através de imposições econômicas exógenas, que tomam a forma de pressões pecuniárias.

As maiores tendências à reversão que os homens da atualidade possuem são as inclinações à atitude predatória, proveniente da fase cultural bárbara, e ao relacionamento de domínio e subserviência pessoal, oriundo da etapa quase pacífica. Isso se dá porque esses dois estágios culturais tiveram uma longa duração na história de todas as etnias que formaram as populações da cultura ocidental, causando uma maior facilidade de persistência dos traços psicológicos dominantes de ambos, influindo na construção dos hábitos mentais desenvolvidos recentemente.

No momento em que ocorre um câmbio que atinge apenas um pequeno aspecto no plano convencional de vida, o consequente desarranjo pode não impactar tanto sobre a comunidade como um todo, podendo até mesmo passar despercebido. Porém, no caso de uma reforma mais radical nas instituições convencionais vigentes, a remodelação necessária será mais relevante e mais perturbadora na ordem social, sofrendo, consequentemente, mais incerteza, resistência e insatisfação por parte das classes afetadas, por conta da aversão à mudança, ao incômodo e ao esforço, decorrentes da necessidade de readequação a hábitos mentais completamente estranhos aos consagrados até então.

Dado que o processo de reestruturação da ordem vigente exige esforço e gasto de energia maior do que a necessária pela luta diária pela sobrevivência, as classes industriais mais pobres possuem dificuldade em empenhar-se a esse reajustamento, tendendo a ser conservadoras e convergindo com os interesses dos membros da classe ociosa, que possuem mais condições para suprimir as possíveis manifestações de mudança, dada a sua preferência pela manutenção da teoria de vida já aceita.

Mais do que isso, a própria desigualdade social constitui um obstáculo a qualquer inovação ou desenvolvimento cultural, visto que a classe ociosa age para 
tornar o comportamento das classes baixas mais conservador, ao ponto de privar-lhes os meios de sustento e, consequentemente, sua energia e poder de consumo, incapacitando-as para a adoção dos novos hábitos.

Ademais, através do exemplo e do preconceito de classe, consegue manter sua situação privilegiada e seus interesses materiais, assim como implantar as normas de respeitabilidade pecuniária e a prática do consumo conspícuo, formulando um padrão de decência na qual todos deveriam seguir, sob pena de sofrer preconceito.

A instituição da classe ociosa, portanto, impossibilita o progresso social e cultural mediante os seguintes instrumentos: a) a inércia da própria classe; b) o exemplo normativo de respeitabilidade pecuniária; c) a presença do consumo conspícuo como padrão de decência; d) o conservantismo; e) o preconceito e a censura à mudança dos hábitos mentais; f) a distribuição de renda desigual; g) e, por fim, o retardamento das mutações ambientais, em contraposição à lei de seleção natural, e a consequente perpetuação das instituições pecuniárias, arcaicas e ultrapassadas.

Visto sob um prisma evolucionário, as noções de "certo" e "errado" expressam uma concordância ou uma discordância em relação ao processo de seleção evolucionário, dividindo a estrutura econômica e social em duas espécies: as instituições de aquisição, exploração, índole conservadora, pecuniária, predatória e parasitária a serviço do interesse econômico invejoso e as instituições de produção, utilidade e industriais a serviço do interesse econômico não invejoso.

As instituições da primeira espécie são aquelas desenvolvidas pela classe ociosa dominante, enquanto as últimas são as pertencentes às classes industriais dominadas, que, em geral, não costumam ser reconhecidas como instituições propriamente ditas, já que a legislação e as normas convencionais tendem a se desenvolver em prol da classe ociosa. Na prática, isso pode ser demonstrado através das leis que defendem e regulam a propriedade privada, a execução dos contratos, as operações financeiras, creditícias e bancárias, os direitos adquiridos, as falências, os acordos sindicais, as relações trabalhistas e os impostos, as quais tendem sempre a favorecer as classes abastadas em detrimento das classes mais baixas, visando a preservação do esquema social e do processo industrial vigentes e, consequentemente, uma exploração pacífica e ordenada (VEBLEN, 1983).

\subsection{A Formação da Classe Ociosa}

A manifestação mais imediata do tipo humano arcaico da fase predatória é o hábito marcial, ou seja, a propensão do homem para a luta e a agressão, que, dentro de um contexto de coletividade, também pode ser denominada de patriotismo.

Tanto a classe ociosa hereditária quanto a classe inferior dos delinquentes possuem esse hábito belicoso. Em comunidades modernas com avançado desenvolvimento industrial, o hábito marcial acabou entrando em caducidade, dado que o espírito predatório não se firmou entre as classes industriais. 
Países mais novos, cuja classe ociosa ganhou novos acréscimos, costumam apresentar menor hábito marcial do que os países mais antigos, cuja classe ociosa é formada por linhagens mais antigas, com inclinações mais aristocráticas.

O espírito marcial também se expressa através da instituição do duelo, que é um recurso utilizado habitualmente e exclusivamente pela classe ociosa para uma luta como resolução universal para diferenças de opinião, como defesa da boa reputação ou afirmação de varonilidade. Somente o cavalheiro da classe ociosa superior e o delinquente da classe ociosa espúria recorrem a esse instrumento, sendo que o homem comum apenas tem luta por causa de alguma irritação momentânea ou exaltação alcoólica, utilizando formas mais simples do instinto de autoafirmação.

Os indivíduos que, em sua evolução espiritual, chegam ao estado adulto, passam, através de uma fase arcaica temporária, ao nível espiritual permanente. O delinquente e o cavalheiro, por sua vez, tiveram seu desenvolvimento espiritual interrompido, ou seja, ainda não se tornaram adultos efetivamente, guardando traços imaturos e predatórios, bem como uma inclinação para a ferocidade emulativa típica dos adolescentes.

A propensão para a emulação predatória ou instinto de esportividade é derivado do instinto primordial de artesanato, porém mais instável que este. As atividades esportivas, tais como o pugilismo, as touradas, o atletismo, a caça, a pesca, o iatismo e os jogos de habilidade, que exigem do indivíduo a competitividade, a astúcia e a agressão, têm esse mesmo caráter de ferocidade emulativa, cujo objetivo é obter reputação de proeza. Os indivíduos que possuem essa tendência para a esportividade têm também um temperamento juvenil de quem obteve um desenvolvimento moral interrompido, e por isso é perceptível a presença do "faz de conta" e da natureza histriônica em todas essas atividades esportivas.

Por ser uma atividade honrosa herdada da cultura predatória, os esportes, a caça e a pesca restaram como únicas formas habituais e tradicionais de recreação ao ar livre a receberem total aprovação honorífica, devido à satisfação de dois requisitos: pela noção de futilidade no dispêndio conspícuo que transmite e pela noção de propósito fornecida pelo instinto de artesanato.

As competições esportivas modernas constituem um processo de autoafirmação fundamentado naquelas características da natureza predatória do homem. O futebol é um exemplo de jogo esportivo que requer contínuo treinamento, diligente apuração e disciplina como forma de intensificar as habilidades e aptidões que podem entrar em obsolescência através da domesticação. O adestramento necessário a esse tipo de esporte, portanto, não apenas melhora o caráter moral, a autoconfiança, o espírito varonil, o físico do competidor e a solidariedade de clã, mas principalmente recupera e exacerba os traços do caráter bárbaro, violento e de esperteza, que servem à autoconservação e à integridade da vida do indivíduo em um âmbito predatório. Contudo, embora sejam elementos essenciais para a 
vida do homem competitivo, não possuem utilidade à comunidade, exceto em relação ao relacionamento hostil perante outras comunidades.

Apesar de haver um sentimento popular defensor dos esportes, há também uma necessidade de legitimar tal sentimento mediante a demonstração de que a sociedade costuma insistir na ideia de que os esportes permitem um hábito mental útil ao trabalho industrial e não emulativo, embora exprimam um temperamento predatório, invejoso, socialmente desintegrante e inútil às atividades industriais.

Nos países ocidentais modernos, os jogos atléticos estão presentes inclusive nas comunidades industriais, mas nelas servem somente como uma mera recreação eventual, não chegando ao ponto de cultivar o hábito esportivo como elemento dominante na formação dos hábitos mentais dessas comunidades. Todavia, quando membros da classe industrial passam a acumular riqueza, a isentar-se do trabalho e, consequentemente, a compor a classe ociosa, costumam se dedicar mais aos esportes e a intensificar seu espírito de esportividade.

Os hábitos mentais populares dominados pelo caráter predatório afetam largamente o padrão de vida econômica coletiva, assim como o seu grau de ajustamento ao ambiente. As duas formas de expressão que a proeza toma na vida do homem bárbaro, a força e a fraude, estão presentes nas guerras modernas, nas ocupações pecuniárias, nos esportes e nos jogos. Ambas aptidões são constantemente preservadas e impulsionadas pelo espírito esportivo, dado que a estratégia e a astúcia tendem a evoluir para a esperteza, a chicana, a falsidade e a intimidação.

Os recursos bárbaros da fraude e da truculência denotam o predomínio de um hábito mental mesquinhamente egoísta, dada a prática de desconsideração pelos interesses alheios, sob o pretexto da conformidade com a lei ou o costume. Ambas características possuem um elevado valor estético e são motivadas pela cultura pecuniária, mas nenhuma delas contém alguma utilidade para a finalidade da vida coletiva.

O hábito mental de crença na sorte é um traço subsidiário do estágio cultural bárbaro, que decorre dos instintos predatório, emulativo e de artesanato e se manifesta no âmbito da predisposição para o hábito esportivo, o jogo e as apostas. Esse senso de probabilidade e sorte, que abrange qualquer jogo de azar ou habilidade, compreende duas fases distintas de um mesmo hábito mental fundamental.

$\mathrm{Na}$ primeira fase, mais arcaica, se introduz - a partir da crença animística, instintiva e teleológica de relações - objetos ou situações aos quais se costuma atribuir uma causa pessoal a fenômenos incompreensíveis, confusos ou imprevistos. Nessa etapa, o indivíduo se apega psicologicamente a talismãs, amuletos, mascotes, ou outros símbolos, que, para ele, por meio de uma mão invisível de índole espiritual ou sobrenatural, auxiliam positivamente no resultado do jogo.

A segunda fase, mais tardia e mais altamente integrada, ocorre por intermédio da explicação dos fatos e fenômenos incompreensíveis baseada em uma personificação antropomórfica. Essa fase é caracterizada por ser um traço arcaico, 
sob o qual o apostador especula sobre o resultado das competições de força ou habilidade, através de seu desejo de aumentar sua torcida, seu lucro ou seu prestígio em relação à perda pecuniária humilhante do apostador perdedor.

Sendo, portanto, um hábito ignorante, egoísta e de comparação invejosa, tem um valor econômico direto e contribui para a utilidade do agente industrial e para o consequente impedimento da eficiência econômica em uma etapa cultural moderna, na medida em que vai no sentido inverso ao processo industrial, que é um processo de causação quantitativa.

O hábito mental de devoção atinge o seu maior desenvolvimento em uma cultura relativamente arcaica, de cultura quase pacífica, por expressar um hábito arcaico de status pessoal, típico do modo de vida predatório. Essa relação de domínio e subserviência se adéqua ao regime de status, mas não ao industrial da atualidade, ou seja, esse hábito se conserva mais nas classes nas quais a vida cotidiana é mais conservadora e mais distante das atividades industriais. Em contrapartida, naquelas classes em que há maior contato com os modernos processos industriais e cujos hábitos de pensamento estão sujeitos a uma força obrigatória de necessidades tecnológicas, o hábito mental de devoção está em obsolescência.

Concomitantemente, esse hábito ganha mais força nas classes das modernas comunidades cuja acumulação de riqueza e ociosidade crescem em maior grau. Nelas, a instituição de uma classe ociosa atua para preservar ou, até mesmo, recuperar o tipo humano de natureza arcaica que a sociedade industrial procurou extinguir através da evolução cultural.

O consumo devoto se relaciona ao consumo vicário, dado que se baseia no princípio da respeitabilidade pecuniária do consumo conspícuo. O traje sacerdotal, os santuários e os acessórios sagrados costumam ser elaborados e ornamentados de forma a transmitir a ideia de abundância, grandeza e alto dispêndio. No entanto, sua estrutura não deve oferecer, pelo menos aparentemente, conforto físico aos seus devotos, que são seus consumidores vicários. Os rituais tendem a ser repetitivos e rápidos, não devendo indicar destreza. O ideal divino, que é comumente aceito pela sociedade, é calcado pelo senso de beleza e de dignidade da população, ou seja, tanto a divindade cultuada quanto os sacerdotes que realizam o culto são idealizados como seres habitualmente ociosos, cujo tempo e esforço devem ser gastos em ocupações não industriais, dado que qualquer traço industrial denota pecado. A postura do sacerdote, além de ociosa, costuma ser distante, superficial e sem conotação sexual.

\section{Considerações Finais}

Este artigo teve como objetivo central apresentar a Teoria da Classe Ociosa, desenvolvida pelo institucionalista Thorstein Veblen. Assim, foram apresentadas 
suas noções evolucionárias de cultura, instintos, hábitos mentais e instituições, as quais reúnem indivíduos e sociedade em uma análise simultaneamente micro e macroeconômica, que combina aspectos da história econômica com o evolucionismo de Charles Darwin, aplicados às instituições.

Em relação às conjecturas levantadas por Veblen (1983), verificou-se que a história da evolução do homem é dividida em cinco estágios culturais, que são descritos como: a) estágio cultural selvagem, que se constitui no estágio cultural mais primitivo, pertencente ao homem selvagem, integrado por grupos diminutos e pobres, pacíficos e sedentários, de estrutura simples e arcaica, cuja economia não tem a propriedade como traço marcante, sendo seus membros incapazes de resistir a ataques de outros povos; b) estágio cultural bárbaro primitivo, que se caracteriza por ser uma sociedade quase pacífica, na qual a propriedade de mulheres do inimigo é utilizada como instrumento emulativo, e que divide a sociedade em funções femininas e masculinas; c) estágio cultural bárbaro intermediário, que se qualifica por uma cultura pacífica, na qual a propriedade se estende para a propriedade de pessoas, incluindo não só as mulheres, mas também os dependentes e os escravos, e as ocupações se dividem entre honoríficas (ociosas) e indignas (trabalhosas, monótonas e frequentes); d) estágio cultural avançado ou feudal, com a propriedade de bens, na qual aparece a distinção entre uma classe ociosa (composta por nobres, sacerdotes e agregados), que se ocupa de atividades não industriais, e uma classe inferior (formada por plebeus), que tem funções estritamente industriais, manuais ou servis; e e) moderna comunidade industrial, que divide a sociedade entre classe ociosa (formada por ricos) e classe trabalhadora vista como inferior (composta pela população pobre), cujo mecanismo emulativo é a riqueza, o sucesso e a acumulação consumista de bens materiais.

Em seguida, esclareceu-se de que forma surge a distinção entre uma classe ociosa e uma classe trabalhadora; a manutenção de uma situação de discriminação e desprezo social, por parte da classe ociosa, partindo-se da ideia de que o trabalho produtivo é vil, humilhante e indigno, não sendo condizente com uma vida espiritual elevada; que a posse de riqueza e poder, evidenciada aos outros em forma de ociosidade conspícua, é um ideal de nobreza e beleza a ser almejado pelos indivíduos decentes, a fim de se obter posição social de status; que, através da procura contínua por riqueza e status pela classe mais pobre, surge uma classe ociosa secundária espúria, que acaba se vendo na mendicidade e na marginalidade da sociedade; que as principais formas de demonstrar ócio conspícuo, para receber prestígio e respeitabilidade pecuniária da sociedade, são as normas de etiqueta e decoro, o exercício de talentos eruditos ou artísticos, o conhecimento de idiomas em desuso, de ciências ocultas, das regras de ortografia, sintaxe e prosódia corretas, da música e outras artes, da moda de vestuário, do mobiliário, de jogos, esportes e animais de raça, como cães e cavalos de corrida; que os indivíduos 
da classe ociosa se motivam pelo instinto de competição, sob os quais precisam demonstrar consumo conspícuo, ou seja, ostentar o consumo supérfluo de bens não produtivos e, ao mesmo tempo, ter o poder de definir e influenciar as tendências da moda e as regras habituais do padrão de vida vigente de todas as classes inferiores, o que pode ser melhor exemplificado pelo consumo de vestuário e o código de comportamento estético; que, semelhantemente à seleção natural sugerida por Charles Darwin, as instituições e os instintos humanos evoluem através de uma seleção natural dos hábitos mentais mais aptos e de um processo cumulativo, adaptativo e obrigatório dos indivíduos a um meio ambiente que muda gradualmente, por meio do progresso social e das mudanças institucionais; e, por fim, que os hábitos mentais marciais, esportista, de crença na sorte e de devoção religiosa, provenientes do instinto predatório do homem, tendem a se preservar ao longo da evolução humana por meio do patriotismo, da propensão para as guerras, do duelo, da prática de esportes, de jogos de azar ou de habilidade, das crenças animística e antropomórfica e da prática de cultos religiosos.

Após esse aprofundamento teórico acerca da temática vebleniana, consegue-se compreender a razão pela qual as sociedades erigem instituições hierárquicas e desiguais como reflexo dos hábitos mentais e das escolhas culturais, morais e comportamentais de seus próprios indivíduos, já que decorrem de padrões socioculturais historicamente constituídos.

\section{Referências}

CONCEIÇÃO, O. A. C. A contribuição das abordagens institucionalistas para a constituição de uma teoria econômica das instituições. Ensaios - FEE, v. 23, n. 1, p. 77-106, 2002a. Disponível em: http://revistas.fee.tche.br/index.php/ensaios/article/view/2029. Acesso em: 25 ago. 2015.

CONCEIÇÃO, O. A. C. O conceito de instituição nas modernas abordagens institucionalistas. Revista de Economia Contemporânea, v. 6, n. 2, p. 119-146, 2002b. Disponível em: http:// www.lume.ufrgs.br/bitstream/handle/10183/23117/000369565.pdf?sequence $=1$. Acesso em: 25 ago. 2015.

FLICK, U. Desenho da pesquisa qualitativa. Porto Alegre: Artmed, 2009.

GIL, A. C. Como elaborar projetos de pesquisa. 4. ed. São Paulo: Atlas, 2008.

HODGSON, G. The approach of institutional economics. Journal of Economic Literature, v. 36, n. 1, p. 166-192, 1998.

HODGSON, G. John. R. commons and the foundations of institutional economics. Journal of Economic Issues, v. 37, n. 3, 2003. Disponível em: http://www.geoffrey-hodgson.info/user/ image/commons.pdf. Acesso em: 02. mai. 2016. 
HUNT, E. K. História do pensamento econômico: uma perspectiva crítica. 2. ed. Rio de Janeiro: Elsevier, 2005.

MONASTERIO, L. M. A economia institucional-evolucionária de Thorstein Veblen. 1995. Dissertação (Mestrado em Economia) - Faculdade de Ciências Econômicas, Universidade Federal do Rio Grande do Sul, Porto Alegre, 1995.

NORTH, D. Institutions. The Journal of Economic Perspectives, v. 5, n. 1, p. 97-112, 1991.

PIMENTEL, J. T. A institucionalidade do "jeitinho brasileiro": regras implícitas ou hábitos dos indivíduos? Uma discussão das abordagens institucionalistas à luz dos intérpretes do Brasil. 2009. Dissertação (Mestrado em Economia) - Faculdade de Ciências Econômicas, Universidade Federal do Rio Grande do Sul, Porto Alegre, 2009. Disponível em: http://www.lume. ufrgs.br/bitstream/handle/10183/22652/000714829.pdf?sequence=1. Acesso em: 15 ago. 2015.

SALLES, A.; PESSALI, H.; FERNÁNDEZ, R. (org.). Economia institucional: fundamentos teóricos e históricos. São Paulo: UNESP. 2017. p. 31-52.

VEBLEN, T. Por que a economia não é uma ciência evolucionária? In: SALLES, A.; PESSALI, H.; FERNÁNDEZ, R. (org.). Economia institucional: fundamentos teóricos e históricos. São Paulo: UNESP, 2017. p. 31-52. Publicação original de 1898.

VEBLEN, T. A teoria da classe ociosa: um estudo econômico das instituições. Paulo: Abril Cultural, 1983, p. 19-91.

Autor correspondente:

Octavio A. C. Conceição

E-mail: octavio@ufrgs.br
Recebido em: 24/01/2018.

Aceito em: 06/07/2019. 